\title{
Le monde des salons. Sociabilité et mondanité à Paris au XVIII ${ }^{\mathrm{e}}$ siècle
}

Éric Saunier

\section{Q OpenEdition \\ 12 Journals}

Édition électronique

URL : https://journals.openedition.org/ahrf/9633

DOI : 10.4000/ahrf.9633

ISSN : 1952-403X

Éditeur :

Armand Colin, Société des études robespierristes

Édition imprimée

Date de publication : 1 juin 2007

Pagination : 225-227

ISSN : 0003-4436

Référence électronique

Éric Saunier, "Le monde des salons. Sociabilité et mondanité à Paris au XVIII siècle », Annales historiques de la Révolution française [En ligne], 348 | Avril-Juin 2007, mis en ligne le 23 juillet 2008 consulté le 27 avril 2022. URL : http://journals.openedition.org/ahrf/9633 ; DOI : https://doi.org/ 10.4000/ahrf.9633

Ce document a été généré automatiquement le 27 avril 2022.

Tous droits réservés 


\title{
Le monde des salons. Sociabilité et mondanité à Paris au XVIII ${ }^{\mathrm{e}}$ siècle
}

\author{
Éric Saunier
}

\section{RÉFÉRENCE}

Antoine Lilti, Le monde des salons. Sociabilité et mondanité à Paris au XVIII siècle, Paris, Fayard, 2005, 568 p., ISBN 35-2492-3, $30 €$.

1 Cet ouvrage, issu d'une thèse soutenue sous la direction de Daniel Roche par Antoine Lilti en 2003, a pour principal objectif d'approfondir la réflexion sur le concept de sociabilité à travers l'étude des mécanismes complexes fondant la distinction sociale et culturelle des salons du Paris des Lumières. S'appuyant sur l'exploitation de sources variées mais accordant un intérêt particulier aux archives policières, particulièrement au fonds du Contrôle des étrangers, l'étude, divisée en quatre parties thématiques, s'ouvre logiquement par un éclairage concernant les pratiques qui fondent la spécificité de la sociabilité salonnière.

2 Dans cette perspective, l'auteur démontre de manière convaincante qu'en dépit de la diversité des situations et de la tendance de l'historiographie à l'intégrer dans le cadre d'une sociabilité curiale aux contours mal définis, le salon est un lieu de sociabilité aisément identifiable dont l'originalité repose sur un ensemble de pratiques parmi lesquelles figurent notamment l'importance de la fonction hospitalière (une finalité qui différencie nettement le salon du café), la régularité des dîners (un aspect qui contribue à rapprocher le salon des formes de la sociabilité bourgeoise), la systématisation de la mixité et la volonté de mettre en valeur une fonction "sociable », la forte codification dont sont l'objet ces pratiques contribuant à renforcer cette originalité.

Les éléments constitutifs de la sociabilité salonnière mis en lumière, Antoine Lilti s'évertue, dans une seconde partie consacrée à l'étude sociologique et topographique de 62 salons parisiens qui ouvrirent leurs portes sous le règne de Louis XVI, à resituer avec précision la place qu'occupe le salon dans l'espace de sociabilité de la capitale. Sur 
le plan sociologique, on soulignera la forte présence des milieux diplomatiques et, $a$ contrario, le faible poids occupé par la magistrature, un phénomène que l'auteur explique par la difficulté de ces robins à concilier la réserve dont ils doivent faire preuve et l'intégration dans un lieu de rencontre où la recherche des promotions entraîne une violence sociale tapageuse. Lieu où se concoctent des alliances et des solidarités vite défaites, le salon se caractérise, sur le plan géographique, par une très forte concentration dans l'espace urbain (le faubourg saint-Germain et le Palais-Royal rassemblant ainsi à eux seuls le tiers des salons parisiens) et par une propension à la mobilité que montre avec prégnance le déplacement vers le nord-ouest de la capitale dont est l'objet sa géographie durant les années 1780. L'instabilité géographique n'empêche pas l'émergence de sensibilités durables. Ainsi, les salons de la rive gauche ouverts "aux pédants de collège et d'étudiants » s'opposent-ils aux salons littéraires plus sérieux établis dans le Quartier Royal. Au-delà de ces différences idéologiques, le salon contribue cependant à construire une microsociété unie par les intérêts réciproques rassemblant la fraction des élites urbaines qui, situées hors de la cour, y assouvit son désir de considération sociale et les hommes de lettres qui trouvent dans ce lieu le moyen de surmonter les difficultés liées au statut de l'écrivain à la fin du siècle des Lumières. Cette relation entraîne la production d'une culture de la domination qui, bien que moins visible qu'à la cour, contribue à canaliser les tensions inhérentes aux élites culturelles à la veille de la Révolution.

La fonction sociétale du salon se développe avec en filigrane la mise en place de " plaisirs » qui donnent naissance à une « culture de la mondanité » alliant le goût du divertissement et la théâtralité des comportements. Son étude est l'objet de la troisième partie de ce livre, une partie qui nous éclaire s'agissant des canaux par lesquels le salon parvint peu à peu à élargir son vivier de recrutement. Les pratiques culinaires, en mettant en place des variantes allant du repas copieux du financier au repas frugal du philosophe, le jeu et les intrigues amoureuses, qui donnent naissance à un art de la contenance plus facile d'accès que celui de la conversation, les pratiques musicales, qui permettent à nombre de professionnels d'accéder au cénacle, sont parmi les plaisirs ceux qui ont facilité le plus cet élargissement social. Celui-ci, à son tour, permet le développement de nouveaux plaisirs. Ainsi, le développement remarquable du théâtre de salon doit-il à la présence dans ce lieu d'aristocrates familiers des divertissements curiaux mais aussi de personnes formées au théâtre de collège et d'amateurs du théatre de foire, lesquels sont les trois groupes qui furent le socle à partir duquel se développa le succès du théâtre au XVIII ${ }^{e}$ siècle. De cet élargissement social, il résulte également que ce lieu de sociabilité fut plus composite que ne le suggère l'image colportée par l'historiographie. La société du salon sait cependant se rassembler, à travers le succès de la poésie galante et ludique, de la correspondance privée ou d'un art de la conversation ouvert à des formes fort variées, dans un commun désir de paraître et d'opérer un travail sur soi.

Ces pratiques culturelles, essentiellement festives et ludiques, n'empêchèrent en rien les progrès d'une politisation dont les formes sont l'objet des analyses proposées dans la dernière partie de l'ouvrage. Présentant la " politique de la mondanité », l'auteur, qui accepte la position des travaux récents visant à réévaluer le rôle du salon durant les années de crise de l'Ancien Régime, s'attache à mettre en évidence l'importance des effets de la production d'une opinion mondaine, et cela même si les formes qu'elle revêtit s'adaptèrent, comme le montre la place importante accordée au ridicule et à la toise, à une culture marquée par la primauté de l'individualisme. Véritable nœud où se 
croisèrent des flux d'information venant de la cour, du monde littéraire, des cafés et des journalistes, le salon put ainsi construire rapidement les carrières politiques, et se muer en foyers d'opposants (le salon de Choiseul à Chanteloup est dans cette perspective l'objet d'une étude fouillée) et surtout en des lieux que les diplomates utilisèrent souvent, à l'instar de Gustave III de Suède, comme une caisse de résonance pour promouvoir la politique de leur pays ou, suivant l'exemple de Stormont et de Benjamin Franklin, comme le lieu d'expression des rivalités.

Comme on le voit, Antoine Lilti réussit au fil des pages le tour de force de renouveler un thème d'étude largement rebattu. Le premier mérite que nous offre son livre est à l'évidence d'avoir su resituer avec une grande précision la place du salon, auprès de l'académie, de la loge et du café dans l'espace de sociabilité parisien. Mais on retiendra également les apports importants de cette thèse dans le domaine de l'histoire sociale, le salon émergeant comme un lieu privilégié ayant permis à la noblesse de cour de reconfigurer sa domination sociale et symbolique grâce à une maîtrise de codes élaborés au sein de ce microcosme. Elle nous éclaire enfin sur la nature des rapports liant les écrivains avec le public : né de la volonté dans l'air du temps de déplacer les pratiques curiales hors du regard du prince, le salon donne naissance à de nouvelles pratiques d'écriture, à une théorisation de l'honnêteté et à la naissance d'une esthétique galante. Pour ces raisons, et pour quelques autres que le lecteur découvrira avec bonheur, le livre d'Antoine Lilti est assurément appelé à devenir un ouvrage de référence sur la sociabilité des Lumières. 